Thorax (1967), 22, 170.

\title{
Empyema due to Klebsiella pneumoniae
}

\author{
J . M. R E I D, R. S. B A R C LAY, J . G. ST EV EN S O N, \\ T. M. WELSH, A N D N. MCSW A N \\ From the Cardio-thoracic Unit, Mearnskirk Hospital, Renfrewshire
}

\begin{abstract}
Three cases of post-pneumonic empyema due to infection with Klebsiella pneumoniae are reported. All were men considerably debilitated by complicating factors. The presence of persistent fistulae and of lung necrosis makes eradication of this infection very difficult and tedious, and in the management of these cases the objective is to secure adequate removal of necrotic tissue, effective drainage, and finally a satisfactory deroofing procedure to obliterate the empyema cavity.
\end{abstract}

The causal organism Klebsiella pneumoniae was first isolated in 1882 by Friedländer. Recent reports of infection with the pathogen have all, without exception, stressed the gravity and very appreciable mortality associated with this type of pneumonia (Gill, 1951 ; Erasmus, 1956 ; Holmes, 1956; Limson, Romansky, and Shea, 1956 ; Oswald, Simon, and Shooter, 1961 ; and Lampe, 1964). In a disease which is notorious for producing destruction of lung tissue with abscess formation, one would expect to encounter a high incidence of complications, particularly with extension of the infection to implicate the pleura. The advent of effective chemotherapy has certainly reduced the mortality, the recommended regimen being streptomycin either alone or in combination with chloramphenicol (Lampe, 1964); but empyema may still occur in some cases.

We wish to present in this communication three patients with $K$. pneumoniae infection who, despite apparently adequate antibiotic treatment, developed empyema. All presented difficult problems of management, and their convalescence was unduly protracted, due in two instances to an accompanying bronchopleural fistula.

\section{CASE REPORTS}

CASE 1 W. M., aged 45 years, was admitted to hospital on 8 November 1965 with a history of productive cough, right-sided chest pain, and fever of one week's duration. He was subject to intermittent bouts of depression and admitted that he was addicted to alcohol. On clinical examination signs of consolidation at the base of the right lung were elicited, and this was confirmed by chest radiography. Initially, ampicillin therapy was administered, but as there was no improvement, chloramphenicol was substituted. This, in turn, had to be discontinued after several days as the patient had developed a generalized bullous skin eruption. Bacteriological examination of the sputum confirmed the presence of a heavy growth of $K$. pneumoniae which was sensitive to chloramphenicol, ampicillin, and cephaloridine, and the patient was then given a course of cephaloridine by intramuscular injection. However, at this juncture there was evidence of a pleural effusion, and as aspiration yielded a substantial quantity of dark brown pus, he was transferred to this unit for surgical treatment.

At operation on 9 December 1965 rib resection and evacuation of the contents of the empyema cavity were performed, following which a large piece of necrotic lung tissue was removed. This left a fistulous area in the underlying lung, and several sutures were inserted into the adjacent lung tissue in an attempt to seal off the fistula. After the skin edges had been sewn down into the margins of the deroofed space, a large pack was placed within. Several days later the pack was removed and tube drainage was instituted, but the tube continued to drain pus for several weeks. Eventually, as the amount of drainage lessened, the tube was shortened to drain into a dressing. A sinogram carried out at $\bar{N}$ this juncture (Fig. 1) showed a residual basal or empyema space, and a further deroofing procedure $N$ (17 January 1966) was necessary, combined with fenestration of the wound to enable daily lavage with aqueous chlorhexidine. Five months from the beginning of the illness, as the wound had not completely healed and as there was still a growth of $K$. pneumoniae from the pus, a third operation was? carried out aimed at eliminating the ledges and grafting the fistulous areas. He made a satisfactory recovery from this procedure.

CASE 2 H. F., aged 63 years, was admitted to hospital on 20 November 1965 with the diagnosis of pneumonia. On admission he was toxic and markedly 


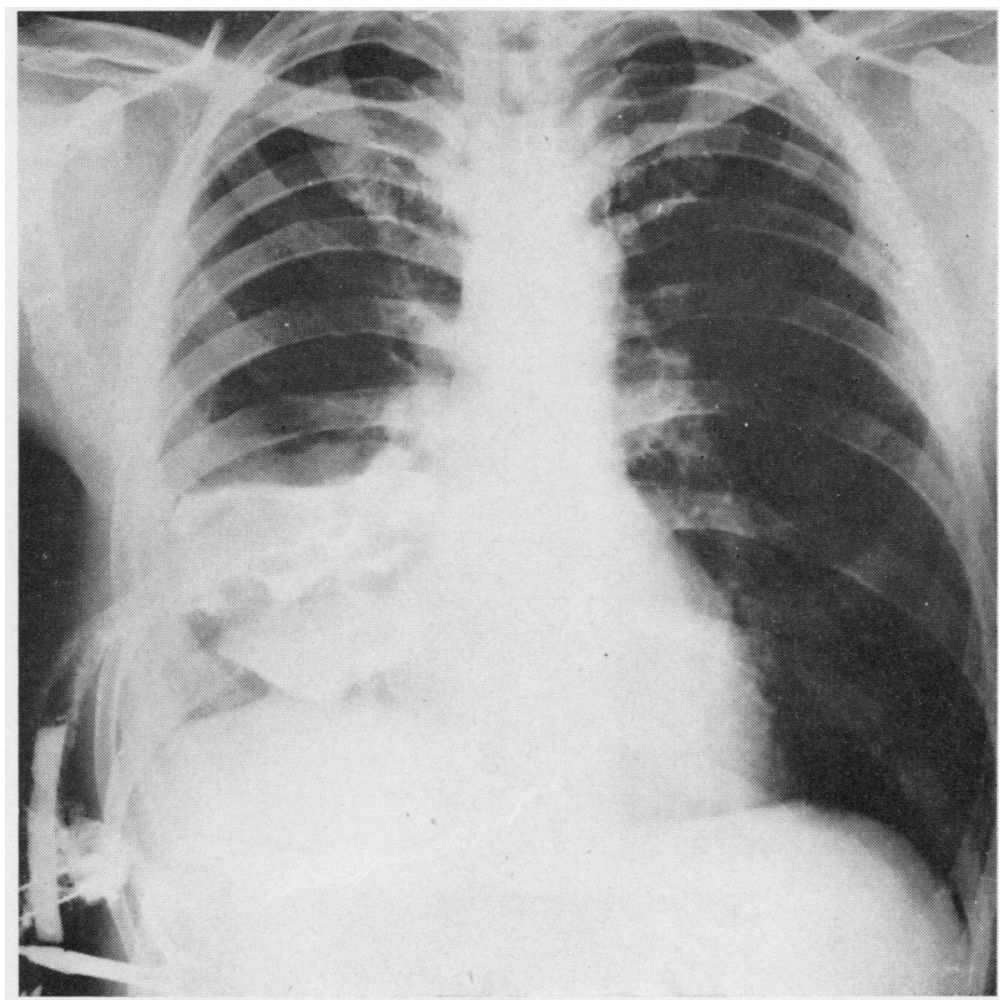

FIG. 1. Case 1. Shows the size of the residual empyema cavity outlined by lipiodol injected through the drainage tube.

febrile, and chest radiography disclosed consolidation of the lower lobe of the left lung (Fig. 2). Sputum examination revealed a heavy growth of $K$. pneumoniae, and treatment with tetracycline and cloxacillin was begun. Although the organism was reported as being sensitive to tetracycline in addition to ampicillin and chloramphenicol, the patient's condition failed to improve, and treatment was switched to chloramphenicol combined with ampicillin. Some improvement occurred in the patient's general condition, but signs of a left-sided pleural effusion became increasingly obvious. Aspiration was performed on several occasions, frank pus being obtained. As more effective drainage was considered necessary, he was transferred here and operation was performed on 14 March 1966. A localized paravertebral space was entered, decorticated, and a $1.5 \mathrm{~cm}$. thick parietal wall was removed. It was noted to contain a thin rind of pulmonary tissue, and the lesion was in fact a pulmonary abscess, the visceral wall consisting of raw lung tissue with several small fistulae. Thereafter the space was washed out with aqueous chlorhexidine, but healing proved very refractory, due in large measure to persistence of the bronchopleural fistulae (Fig. 3). After a lengthy period the wound is now healing satisfactorily, and his general condition is markedly improved.

CASE 3 (T. D.) Following an attack of pneumonia in January 1966, this patient, a man aged 59 years, developed an empyema (Figs 4 and 5). Bacteriological examination of the pleural aspirate was positive for $K$. pneumoniae, the organism being sensitive to streptomycin, tetracycline, and chloramphenicol but resistant to penicillin and erythromycin. At surgical exploration on 23 March a localized paravertebral space with a very thick cortex was entered, and this was deroofed and laid open. There were no overt fistulae. Although daily lavage of the space produced lessening in the amount of discharge, with decrease in the size of the empyema cavity, a further deroofing procedure proved necessary six weeks later (Fig. 6), and since then there has been gradual improvement in his overall condition.

\section{DISCUSSION}

Klebsiella pneumoniae is a Gram-negative organism with a thick capsule and in certain of its characteristics resembles the pneumococcus. According 


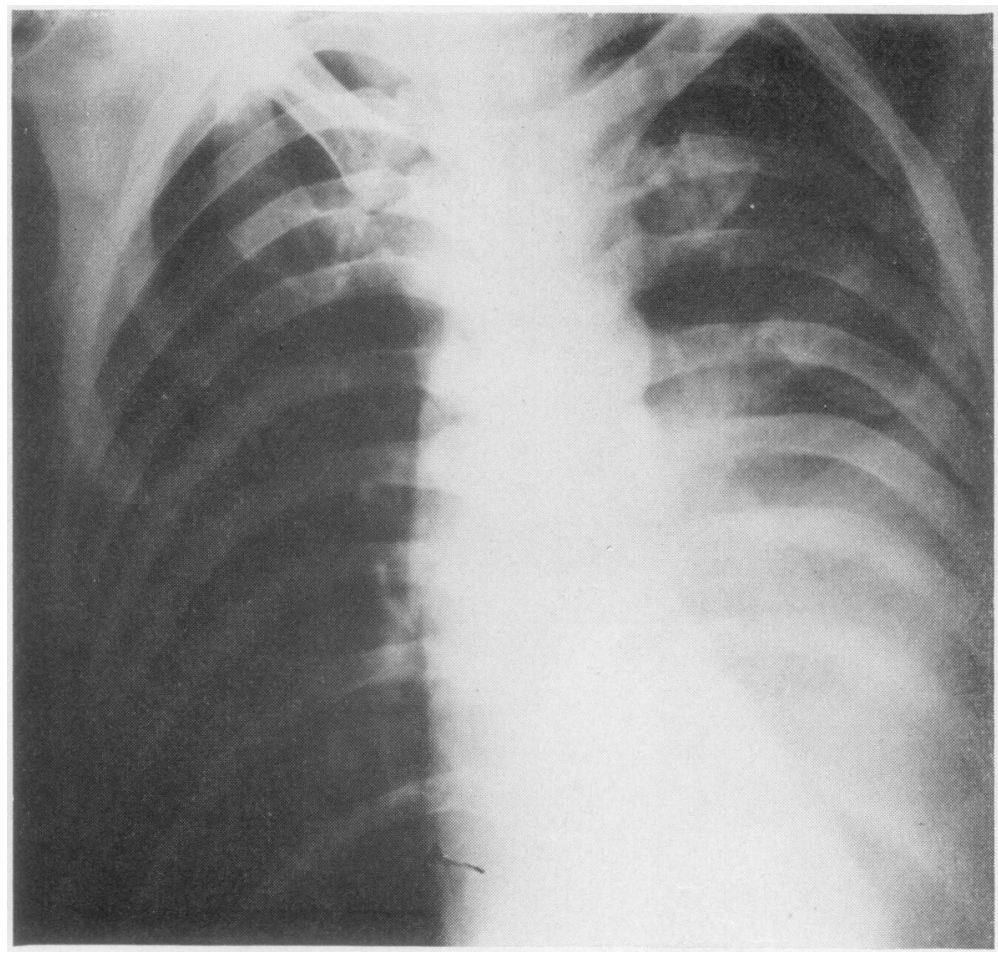

FIG. 2. Case 2. Shows consolida- $\overrightarrow{\overrightarrow{2}}$ tion of the lower lobe of the left lung.

FIG. 3. Case 2. Shows the size of the empyema cavity following deroofing and drainage.

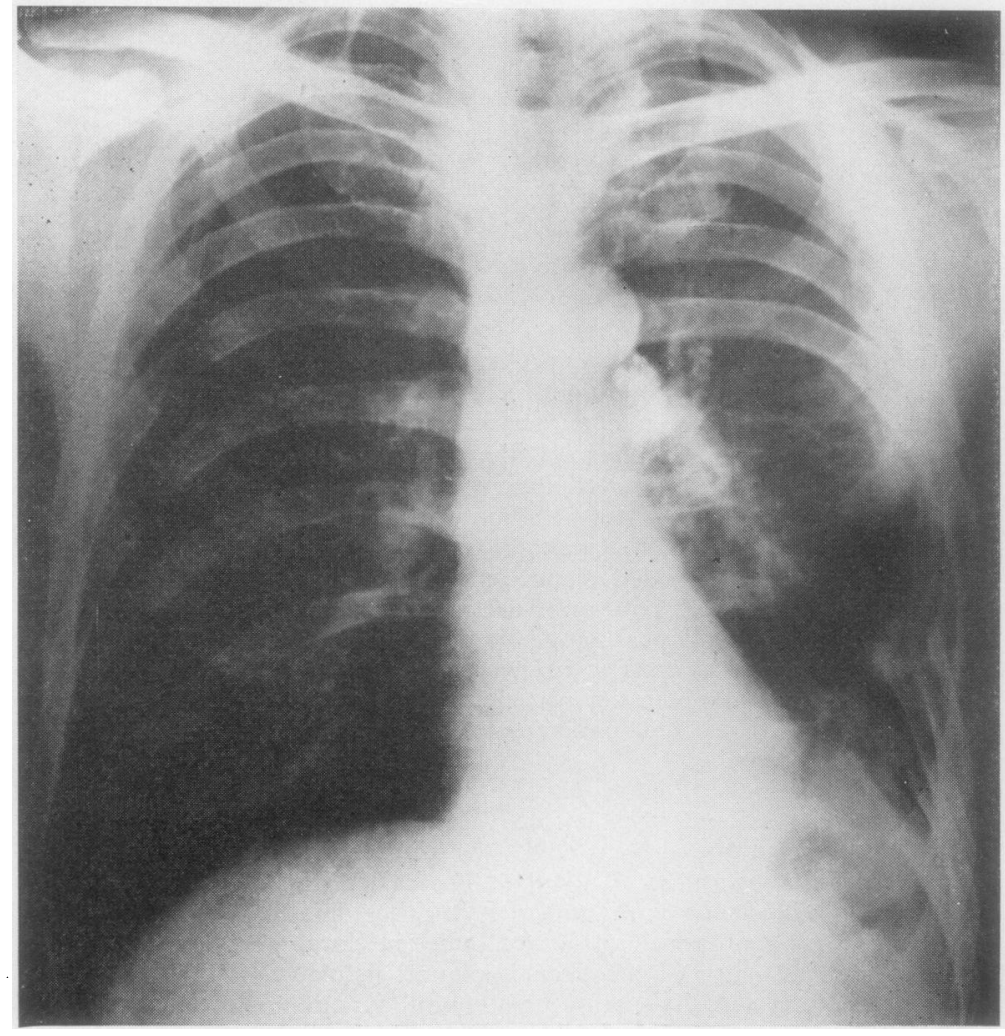

. 


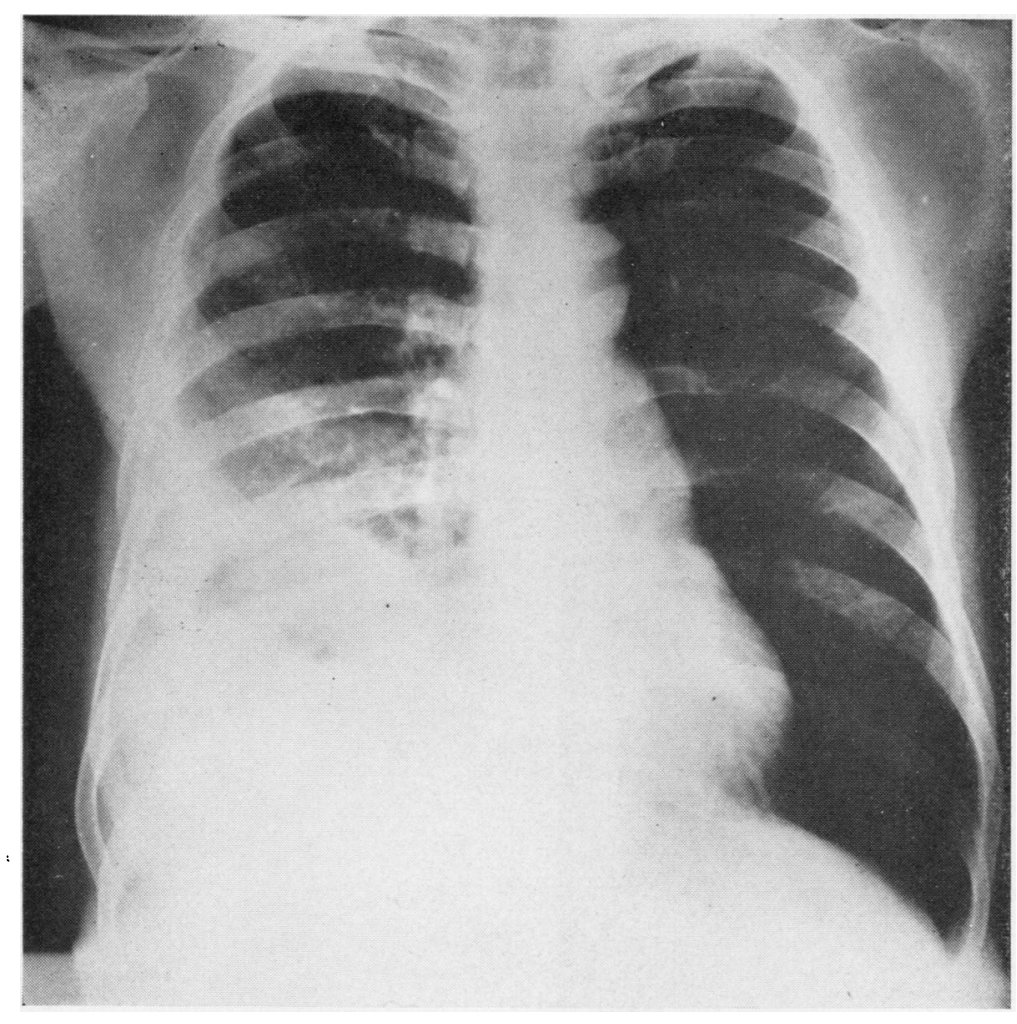

FIG. 4. Case 3. The persistent consolidation in the lower lobe of the right lung and overlying empyema.

FIG. 5. Case 3. At a later stage of development of the empyema before surgical treatment.

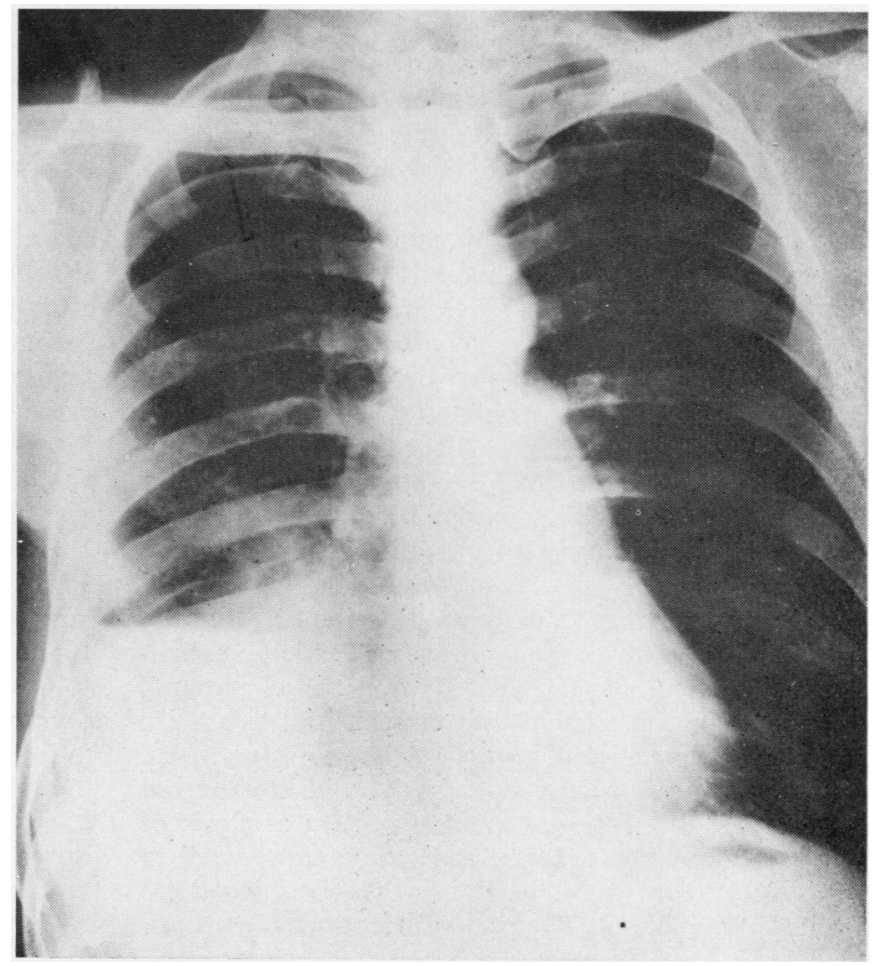




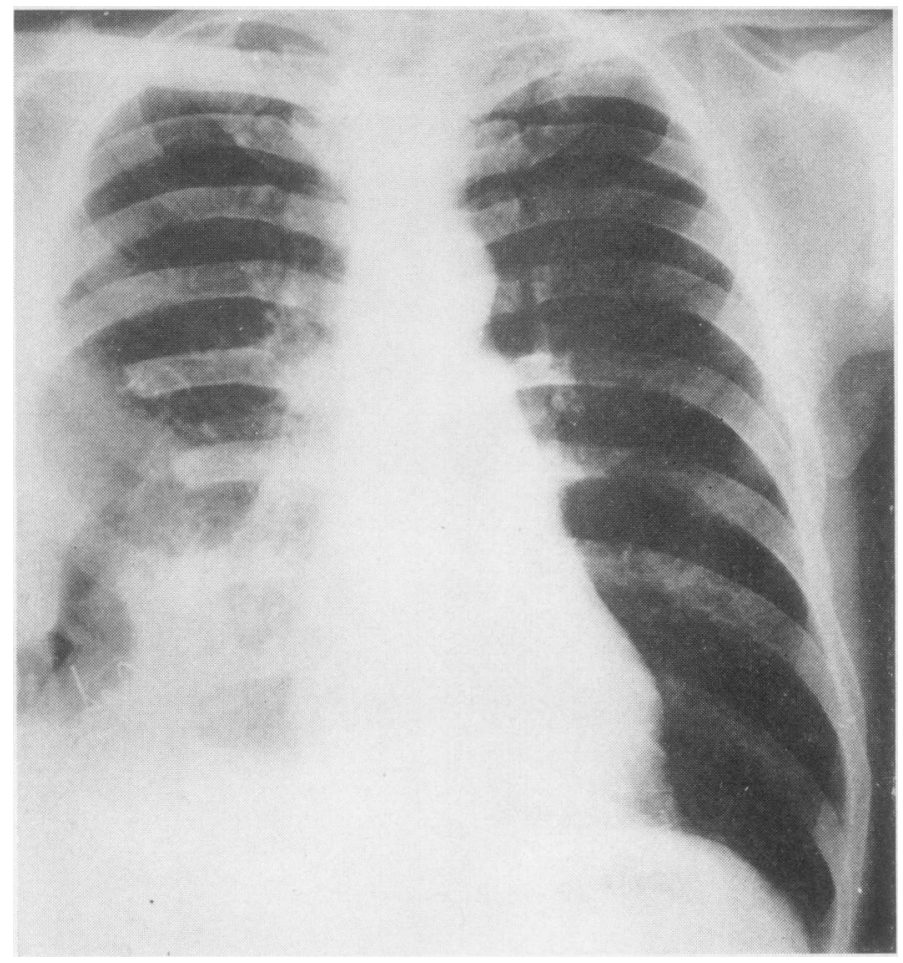

FIG. 6. Case 3. Chest radiograph beforei discharge after deroofing and drainage of $\vec{\nabla}$ the empyema space.

to Marshall and Perry (1952) it is responsible for less than $1 \%$ of all cases of pneumonia, and Bullowa and Gleich (1938), reviewing a series of 4,907 cases of pneumonia in New York between 1928 and 1935 , encountered only 36 due to this organism, representing an incidence of $0.71 \%$. Lampe (1964), in a retrospective analysis of an even larger series of 7,117 , reported a similar percentage. By and large it afflicts predominantly older patients, particularly those debilitated by either chronic disease or chronic alcoholism (Marshall and Perry, 1952; Greenberg and Kahn, 1963 ; and Lampe, 1964). Greenberg and Kahn (1963) estimated that abscess formation occurred in $50 \%$ of patients with chronic $K$. pneumoniae infection, and of these one-third developed empyema. Of the 45 patients described by Lampe (1964), three developed empyema which necessitated surgical drainage. Of the three patients reported in the present communication, two were past middle age and two were known alcoholics. All three cases occurred recently, within a period of several months, and a retrospective analysis of 180 cases of non-tuberculous empyema treated in this unit from 1950 to the present disclosed no other instance of Klebsiella infection. The anti- biotic of choice recommended for $K$. pneumoniae is chloramphenicol, either alone or in combina-o tion with streptomycin (Lampe, 1964); but this was administered to our patients at a compara-ō tively late stage of their illness and may well $\underset{x}{\mathbb{D}}$ explain the development of empyema. Once chronic infection of the pleural cavity is established, the problem of eradicating it is indeedo formidable. Le Roux (1965), in a retrospective 3 review of 500 patients with thoracic empyemao extending over a 12-year period, recommended formal thoracotomy with decortication in reason-o ably fit patients, reserving open drainage by rib resection for frail or very ill patients.

However, in our patients decortication was not applicable, due to the concomitant infection in the N lung parenchyma with abscess formation. In caseso 1 and 3 the infected pleural cavity was drained following which a deroofing procedure proved necessary. Lung abscess was the principal lesiono in our second case, and this was treated by a modified form of decortication and removal of a portion of necrotic lung tissue. A segment of lower lobe containing an abscess was also excised in case 2. Despite daily lavage of the residua? cavity with chlorhexidine, healing has been verye 
prolonged due to a persistent bronchopleural fistula in association with areas of necrotic lung tissue. We have successfully used chloramphenicol succinate in previous cases of empyema (Stevenson, Reid, McFarlane, and Barrie, 1961), the drug in the form of a suspension being instilled directly into the pleural cavity, but it proved of only temporary benefit when used in these three patients. It did not produce any substantial reduction in the size of the empyema cavity, and further surgical procedures have been necessary.

Our policy in coping with patients suffering from empyema who require surgical intervention is to carry out rib resection and drainage, decortication, deroofing, or a combination of two or more of these procedures. These measures suffice in most patients with non-tuberculous empyema, but empyema caused by $K$. pneumoniae is very intractable, due in large measure to the underlying areas of lung necrosis and to the presence of persistent bronchopleural fistulae. Despite successive procedures designed to secure adequate drainage, to remove necrotic tissue, and to close the fistulae, the condition has been unduly recalcitrant in all three. Fairly extensive and mutilating operations on the chest wall have been imperative, but they have been justified by the overall improvement in the patients' general condition and the slow but steady reduction in the dimensions of the empyema space. All three patients are now ambulant and reasonably fit, although admittedly still having daily dressings to their wounds.

The authors wish to thank the various physicians in the area who referred their patients for further treatment. They are also indebted to Mr. Gray, Department of Medical Illustration, Victoria Infirmary, for reproducing the radiographs.

\section{REFERENCES}

Bullowa, J. G. M., and Gleich, M. (1938). A comparison of the etiology, death rates and bacteremic incidence in the more frequent primary pneumonias of infants, children, and adults. Amer. J. med. Sci., 196, 709.

Erasmus, L. D. (1956). Friedländer bacillus infection of the lung. Quart.J. Med., 25, 507.

Gill, R. J. (1951). Treatment of Friedländer's pneumonia. Amer. J. med. Sci., 221, 5.

Greenberg, L. F., and Kahn, S. B. (1963). Klebsiella pneumonia with pneumothorax, pneumomediastinum, and pneumoperitoneum. Report of a case. Dis. Chest, 43, 546.

Holmes, R. B. (1956). Friedländer's pneumonia. Amer. J. Roentgenol., 86,728 .

Lampe, W. T. (1964). Klebsiella pneumonia. A review of 45 cases and re-evaluation of the incidence and antibiotic sensitivities. Dis. Chest, 46, 599.

Le Roux, B. T. (1965). Empyema thoracis. Brit. J. Surg., 52, 89.

Limson, B. M., Romansky, M. J., and Shea, J. G. (1956). An evaluation of 22 patients with acute and chronic pulmonary infection with Friedländer's bacillus. Ann. intern. Med., 44, 1070.

Marshall, G., and Perry, K. M. A. (1952). Diseases of the Chest, vol. I. Butterworth, London.

Oswald, N. C., Simon, G., and Shooter, R. A. (1961). Pneumonia in hospital practice. Brit. J. Dis. Chest, 55, 109.

Stevenson, J. G., Reid, J. M., McFarlane, N., and Barrie, J. D. (1961). The value of chloromycetin succinate used topically in intrathoracic suppuration. Ibid., $\mathbf{8 5}, 216$. 